\section{Confounding by indication and ethnicity difference? Comment on 'Hypersensitivity reactions with allopurinol and febuxostat: a study using the Medicare claims data'}

We read with great interest the study by Singh and Cleveland ${ }^{1}$ that investigated the risk of hypersensitivity reactions (HRs) with allopurinol and febuxostat using Medicare claims data. These authors analysed a national cohort in the 5\% Medicare beneficiary sample randomised from 2006 to 2012 of adults older than 65 years who experienced a new treatment episode with allopurinol, febuxostat or colchicine. They reported the following incidence rates for HRs: allopurinol, 23.9; febuxostat, 30.5; and colchicine, 25.7 cases per 1000 person-years. Combination treatments of febuxostat+colchicine, allopurinol+colchicine and febuxostat+colchicine +allopurinol increased the incidence of HRs to 56.8, 27.4 and 89.1 per 1000 person-years, respectively. Based on a propensity-matched analyses of allopurinol versus febuxostat $(5: 1)$, which showed febuxostat with an HR of 1.25 (95\% CI 0.93 to -1.67 ), the study concluded there was no difference between the HRs for allopurinol versus febuxostat. However, some study results and aspects of these findings must be clarified.

First, Lin $e t a l^{2}$ reported a higher incidence rate of HRs with allopurinol versus febuxostat (15.37 vs 3.48 per 1000 personyears, respectively), which differs from the conclusion reached by Singh et al. In clinical practice, physicians are generally concerned about the potential adverse effects of allopurinol, such as Steven-Johnson syndrome for their older adult patients or those who have chronic kidney disease, leading them to choose febuxostat versus allopurinol. This choice may cause an overestimation of the rate of HRs with febuxostat and even doubts of confounding by indication.

Regarding ethnicity, Lu et $a l^{3}$ found that white patients have lower frequencies of human leucocyte antigen-B*5801 in the USA compared with Asian patients, which correlates with a lower risk for Stevens-Johnson syndrome in white patients and may result in the study showing a lower incidence of HRs in a predominantly white population.

Another key issue for the study by Singh et al is that several numeric discrepancies appear in the text versus the abstract. For example, the abstract stated the crude incidence rates of HRs by drug as follows: allopurinol, 23.7; febuxostat, 30.7; and colchicine, 25.6 cases per 1000 person-years. However, the Results section and table 2 in the text by Singh et al, these values are listed as $23.9,30.5$ and 25.7 , respectively.

Finally, the discussion about the safety of allopurinol, febuxostat and colchicine is an important issue that must be addressed by further research.
Po-Ke Hsu $\odot$, 1,2 Yung-Heng Lee, ${ }^{3,4,5,6}$ James Cheng Chung Wei $\overbrace{}^{2,7,8}$

${ }^{1}$ Department of Gastroenterology, Changhua Christian Medical Foundation Changhua Christian Hospital, Changhua City, Taiwan

${ }^{2}$ Institute of Medicine, Chung Shan Medical University, Taichung, Taiwan

${ }^{3}$ Department of Health Services Administration, China Medical University, Taichung, Taiwan

${ }^{4}$ Department of Public Health, China Medical University, Taichung, Taiwan ${ }^{5}$ Department of Orthopedics, Cishan Hospital, Ministry of Health and Welfare, Kaohsiung, Taiwan

${ }^{6}$ Department of Center for general education, National United University, Miaoli, Taiwan

${ }^{7}$ Department of Allergy, Immunology and Rheumatology, Chung Shan Medical University Hospital, Taichung, Taiwan

${ }^{8}$ Graduate Institute of Integrated Medicine, China Medical University, Taichung, Taiwan

Correspondence to Dr James Cheng Chung Wei, Institute of Medicine, College of medicine, Chung Shan Medical University, Taichung 404, Taiwan; jccwei@gmail.com

Contributors All authors contributed equally to the presented work.

Funding The authors have not declared a specific grant for this research from any funding agency in the public, commercial or not-for-profit sectors.

Competing interests None declared.

Patient and public involvement Patients and/or the public were not involved in the design, conduct, reporting or dissemination plans of this research.

Patient consent for publication Not required.

Provenance and peer review Not commissioned; internally peer reviewed.

(c) Author(s) (or their employer(s)) 2020. No commercial re-use. See rights and permissions. Published by BMJ.

\section{Check for updates}

To cite Hsu P-K, Lee Y-H, Wei JCC. Ann Rheum Dis Epub ahead of print: [please include Day Month Year]. doi:10.1136/annrheumdis-2020-218056

Received 19 May 2020

Revised 26 May 2020

Accepted 26 May 2020

\section{SLinked}

- http://dx.doi.org/10.1136/annrheumdis-2020-218150

Ann Rheum Dis 2020;0:1. doi:10.1136/annrheumdis-2020-218056

\section{ORCID iDs}

Po-Ke Hsu http://orcid.org/0000-0003-0828-5680

James Cheng Chung Wei http://orcid.org/0000-0003-0310-2769

\section{REFERENCES}

1 Singh JA, Cleveland JD. Hypersensitivity reactions with allopurinol and febuxostat: a study using the Medicare claims data. Ann Rheum Dis 2020;79:529-35.

2 Lin C-W, Huang W-I, Chao P-H, et al. Risk of cutaneous adverse reactions associated with allopurinol or febuxostat in real-world patients: a nationwide study. Int J Clin Pract 2019;73:e13316.

3 Lu N, Rai SK, Terkeltaub R, et al. Racial disparities in the risk of Stevens-Johnson syndrome and toxic epidermal necrolysis as urate-lowering drug adverse events in the United States. Semin Arthritis Rheum 2016;46:253-8. 